\title{
Hypothalamic BMP9 suppresses glucose production by central PI3K/Akt/mTOR pathway
}

\author{
Yirui He1,2,*, Cheng Zhang1,*, Yong Luo1, Jinhua Chen², Mengliu Yang1, Ling Li ${ }^{\mathbb{D} 3}$, Harvest F Gu4, Gangyi Yang ${ }^{\mathbb{D} 1,2}$ and \\ Xianxiang Zhang1 \\ ${ }^{1}$ The Center of Clinical Research of Endocrinology and Metabolic Diseases in Chongqing and Department of Endocrinology, Chongqing Three Gorges \\ Central Hospital, Chongqing, China \\ 2Department of Endocrinology, The Second Affiliated Hospital, Chongqing Medical University, Chongqing, China \\ ${ }^{3}$ Key Laboratory of Diagnostic Medicine (Ministry of Education) and Department of Clinical Biochemistry, College of Laboratory Medicine, Chongqing \\ Medical University, Chongqing, China \\ 4Department of Clinical Science, Intervention and Technology, Karolinska University Hospital, Karolinska Institutet, Huddinge, Stockholm, Sweden
}

Correspondence should be addressed to G Yang or X Zhang: gangyiyang@hospital.cqmu.edu.cn or xianxiangzhangcqsx@126.com

*(Y He and C Zhang contributed equally to this work)

\begin{abstract}
Bone morphogenetic proteins (BMPs) are secreted ligands that belong to the transforming growth factor- $\beta$ (TGF- $\beta$ ) superfamily. BMP7 has been reported to play a role in reversing obesity and regulating appetite in the hypothalamus. Whether BMP9 plays a central role in regulating glucose metabolism and insulin sensitivity remains unclear. Here, we investigated the impact of central BMP9 signaling and possible route of transmission. We performed intracerebroventricular (ICV) surgery and injected adenovirus expressing BMP9 (Ad-BMP9) into the cerebral ventricle of mice. Metabolic analysis, hyperinsulinemic-euglycemic clamp test, and analysis of phosphatidylinositol 3,4,5-trisphosphate (PIP3) formation were then performed. Real-time PCR and Western blotting were performed to detect gene expression and potential pathways involved. We found that hypothalamic BMP9 expression was downregulated in obese and insulinresistant mice. Overexpression of BMP9 in the mediobasal hypothalamus reduced food intake, body weight, and blood glucose level, and elevated the energy expenditure in high-fat diet (HFD)-fed mice. Importantly, central treatment with BMP9 improved hepatic insulin resistance (IR) and inhibited hepatic glucose production in HFD-fed mice. ICV BMP9-induced increase in hepatic insulin sensitivity and related metabolic effects were blocked by ICV injection of rapamycin, an inhibitor of mammalian target of rapamycin (mTOR) signaling. In addition, ICV BMP9 promoted the ability of insulin to activate the insulin receptor/phosphoinositide 3-kinase (PI3K)/Akt pathway in the hypothalamus. Thus, this study provides insights into the potential mechanism by which central BMP9 ameliorates hepatic glucose metabolism and IR via activating the mTOR/PI3K/Akt pathway in the hypothalamus.
\end{abstract}
Key Words
- BMP9
- glucose metabolism
- hypothalamus
- insulin resistance
- mTOR 


\section{Introduction}

The global prevalence of obesity and type 2 diabetes mellitus (T2DM) is increasing. These two diseases are associated with insulin resistance (IR) and disrupted lipid and glucose metabolism (Saltiel \& Kahn 2001). To understand the molecular mechanism underlying IR, a large number of studies have investigated the role of insulin signaling molecules in the liver, muscle, and fat over the past decades (Schenk et al. 2008). Hormones secreted from different tissues, such as adiponectin from the adipose tissue and fibroblast growth factor- 21 from the liver, were found to be involved in the regulation of insulin sensitivity and energy metabolism (Kadowaki et al. 2006). In recent years, several reports have demonstrated that the CNS, particularly the hypothalamus, plays a key role in modulating insulin sensitivity and energy homeostasis in vivo (Knight et al. 2011, Purkayastha et al. 2011, Yang et al. 2012). Furthermore, changes in the levels of some nutrients and hormones in the hypothalamus have been found to regulate glucose and lipid homeostasis in vivo (Lam et al. 2011, Wu et al. 2014, Luo et al. 2016). Further investigation on the role of CNS, including the hypothalamus, in hormone signaling, is important for better understanding the pathogenesis of obesity and T2DM.

Bone morphogenetic proteins (BMPs) are secreted ligands that belong to the transforming growth factor- $\beta$ superfamily. They not only function as developmental factors in embryonic development and growth differentiation but also play a role in adipocyte development and energy metabolism (Chen et al. 2004, Yamamoto \& Oelgeschlager 2004, Kishigami \& Mishina 2005, Tobin \& Celeste 2006, Schulz \& Tseng 2009). Interestingly, several BMP ligands have been found to be present in the cerebrospinal fluid and expressed in the hypothalamus (Dattatreyamurty et al. 2001, Ohyama et al. 2008). Furthermore, different BMP receptor isoforms have been identified throughout the brain (Ebendal et al. 1998), suggesting that BMP signaling might regulate hypothalamic function. Townsend et al. (2012) conducted a study with $\mathrm{db} / \mathrm{db}$ and ob/ob mice and observed that BMP7 reversed obesity and regulated appetite through a central mammalian target of rapamycin (mTOR) pathway. In addition, BMP8B was found to be expressed in brown adipose tissue (BAT) and the hypothalamus, and central treatment with BMP8B increased thermogenesis via neuronal activation of regulatory nuclei in the hypothalamus (Whittle et al. 2012). In the peripheral tissues, BMP8B was found to increase thermogenesis by inducing white adipose tissue (WAT) browning (Martins et al. 2016, Pellegrinelli et al. 2018). Recently, Mahli et al. (2019) reported that BMP8B was related to fatty acid uptake and de novo lipogenesis in the liver.

BMP9 is mainly expressed in non-parenchymal hepatocytes, like endothelial and stellate cells, and can bind to a specific receptor on the hepatocytes (Song et al. 1995, Miller et al. 2000). Initially, Caperuto et al. (2008) showed that BMP9 might play a role in the regulation of glucose metabolism and insulin signaling. Later, Kuo et al. (2014) demonstrated that the administration of BMP9 antibodies-induced glucose intolerance and IR in rats. Peripheral treatment with MB109, a BMP9 analog, was shown to decrease weight gain in high-fat diet (HFD)fed mice by reducing the size of white adipocytes and decreasing fasting blood glucose (FBG) levels without changing food intake or apparent behavioral performances. MB109 treatment also increased the expression of the browning-related genes in the subcutaneous fat of HFDfed mice. In addition, MB109 enhanced the expression of genes related to hepatic fatty acid synthase in obese mice (Kuo et al. 2014). In the CNS, BMP9 was also found to be a potent inducer of the cholinergic phenotype (LopezCoviella et al. 2000). Recently, we have been reported that circulating BMP9 levels are markedly lower in newly diagnosed patients with T2DM compared with those in healthy subjects (Luo et al. 2017).

Based on accumulating evidence as described previously, we hypothesized that BMP9 might be expressed in the hypothalamus and play a central role in glycoregulation and IR in obesity and T2DM. To test this hypothesis, we investigated the impact of intracerebroventricular (ICV) injection of BMP9 on glycoregulation and hepatic insulin signaling and further explored the possible underlying mechanisms.

\section{Materials and methods}

\section{Animal preparation}

Male C57BL/6J (cWT), db/db and adiponectin knockout (Adipoq $^{-/-}$) mice were purchased from Experimental Animal Centers of Chongqing University of Medical Sciences and Shanghai Biomodel or Ganismsci \& Tech Develop Co., Ltd. Shanghai, China, respectively. All animals were adapted to feed for 7 days. In this study, 8-week-old WT and Adipoq-/mice were fed with either normal chow diet (NCD, $10 \%$ calories from fat) or HFD ( $45 \%$ of calories from fat; Medicine Inc. Jiangsu, China) for 12 weeks. The animals were fed in humidity and temperature controlled rooms 
with free access to food and water. In the study, all kinds of treatments for mice were specifically approved and strictly carried out in accordance with the administrative animal management method of Chongqing Medical University, and at the same time, all the experiments were approved and performed according to the protocols established by Ethics Committee of Chongqing Medical University (Reference Number: 2017020).

\section{Construction of recombinant adenovirus vectors}

Adenovirus expressing BMP9 (Ad-BMP9) and encoding enhanced green fluorescence protein (Ad-GFP, as a control) were generated using the AdEasy Adenoviral Vector System (Qbiogene) as previously reported (Li et al. 2011). The sequence designed for Ad-BMP9 is sense: 5'-CTCGGATCCATGTGTCCTGGGGCACTGTGG-3' and antisense: 5'-CTCTCTAGACTACCTG CACCCACACTCTGC-3'. Large-scale amplification and purification of recombinant adenoviruses were performed with the Vira Bind Adenovirus Purification Kit, according to the manufacturer's instructions (Cell Bio Labs, San Diego, CA, USA).

\section{Intracerebroventricular (ICV) surgery and hepatic branch vagotomy (HVG)}

Seven days before the hyperinsulinemic-euglycemic clamps (HECs), mice were anesthetized and fixed in a stereotaxic apparatus. A stainless steel guide cannula (62204, RWD life science, China) was implanted into the third ventricle of the cerebrum (coordinates $-1.40 \mathrm{~mm}$ anteroposterior, $0.00 \mathrm{~mm}$ lateral and $5.40 \mathrm{~mm}$ dorsoventral from bregma) of WT mice, then fixing the catheter with glass ionomer cement. $24 \mathrm{~h}$ after cannula implant, an amount of $2 \mu \mathrm{L}$ $\left(5 \times 10^{9} \mathrm{pfu} / \mathrm{mL}\right)$ of Ad-BMP9 or Ad-GFP was injected slowly and uniformly into the third ventricle of mice within 5 min (Kooijman et al. 2015). Following the infusion, the guide cannula remained inserted for approximately $5 \mathrm{~min}$ to allow the drug to diffuse away from the cannula tip. In four subgroups of mice, the cannula was then implanted into the third ventricle of the brain for rapamycin (R0395 -1 MG, Sigma) or DMSO treatment. Three days later, a Silastic catheter (0.02 ID, Dow Corning Corporation, MI, USA) was placed in the internal jugular vein for sampling during the hyperinsulinemic-euglycemic clamp (HEC), glucose tolerance tests (GTT), and insulin tolerance tests (ITT). Another polyethylene catheter (PE50+PE10, Smiths Medical ASD, Inc, USA) was placed in the left carotid artery. To prevent blood coagulation, catheters were flushed with $300 \mu \mathrm{L}$ of isotonic saline containing heparin $(20 \mathrm{U} / \mathrm{mL})$ and ampicillin $(5 \mathrm{mg} / \mathrm{mL})$ and then filled with a viscous solution of heparin (300 $\mathrm{U} / \mathrm{mL}$ ) and $80 \%$ polyvinylpyrrolidone (PVP-10, Fisher Scientific, Pittsburgh, PA). For the study of the mTOR signal pathway, Rapamycin or DMSO was slowly injected into ICV $(20 \mu \mathrm{g} / 2 \mu \mathrm{L} / 5 \mathrm{~min}) 3 \mathrm{~h}$ before the in vivo experiments. For the HVG study, separate cohorts of mice were subjected to HVG or sham operation (SHAM), as previously reported (Luo et al. 2016). Briefly, an incision was made into the ventral midline. The hepatic branch of the ventral subdiaphragmatic vagal trunk was identified and transected by microcautery, severing and cauterizing the hepatic vagus. SHAM control mice underwent the same procedure except for the transection of the nerve.

\section{Metabolic analyses}

Mice were single-housed after adenovirus injection. Body weight and food intake were measured daily for 2 weeks. After the mice were adapted for $24 \mathrm{~h}$ in a computercontrolled calorimetry system (MM-100 CWE Inc., PA, USA), 24-h oxygen consumption $\left(\mathrm{VO}_{2}\right)$, the volume of carbon dioxide produced $\left(\mathrm{VCO}_{2}\right)$, and energy expenditure were measured every $10 \mathrm{~min}$ for $24 \mathrm{~h}$ on the day 7 after adenovirus injection. The respiratory exchange ratio was calculated as the RER $=\mathrm{VO}_{2} / \mathrm{VCO}_{2}$. The Data is represented as the means obtained in these records. Blood pressure was measured by the tail-cuff method with the BP-2010A system (Softron Biotechnology, Beijing, China).

\section{Glucose (GTTs) and insulin tolerance tests (ITTs)}

GTTs and ITTs were performed by intraperitoneal injection of $2 \mathrm{~g} / \mathrm{kg}$ glucose after overnight fasting (12 h) and 0.75 units $/ \mathrm{kg}$ insulin after $4 \mathrm{~h}$ fasting, respectively, as previously described (Luo et al. 2016). Four subgroups of mice fed with HFD were subjected to ICV injection with rapamycin $(20 \mu \mathrm{g} / 2 \mu \mathrm{L})$ or the vehicle (DMSO) $2 \mathrm{~h}$ before the start of the GTT (Stevanovic et al. 2013). During the GTT and ITT, blood glucose was measured in indicated time points (including $0,15,30,60,90$, and $120 \mathrm{~min}$ ).

\section{Hyperinsulinemic-euglycemic clamp studies (HECs)}

After fasting for $10 \mathrm{~h}$, HECs were performed in conscious and unrestrained mice as previously reported (Li et al. 2009, Wu et al. 2014). Briefly, HPLC-purified [3-3 $\mathrm{H}]$ glucose was infused through the jugular vein catheter starting at 0 min with a bolus $(5 \mu \mathrm{Ci})$ followed by a 
continuous infusion $(0.05 \mu \mathrm{Ci} / \mathrm{min})$ for $90 \mathrm{~min}$ (basal period) to estimate the rate of basal glucose turnover. Following the basal period, a 2-h HEC was conducted with a primed, continuous infusion of human insulin $(5 \mathrm{mU} /$ $\mathrm{kg} / \mathrm{min}$ ) (Humulin; Eli Lilly Co., Indianapolis, IN, USA) to raise plasma insulin levels, while plasma glucose was maintained at basal concentrations with variable rates of $20 \%$ glucose infusion. The basal/clamped periods were 90/120 min (Fig. 3C). At the end of the HEC, mice were killed, and tissues were freeze-clamped in situ and stored at $-160^{\circ} \mathrm{C}$ for subsequent analysis.

\section{In vivo glucose uptake}

Glucose uptakes in fat and muscle tissues were examined as previously reported (Boini et al. 2006). Briefly, mice for fasting $12 \mathrm{~h}$ were injected intraperitoneally with 2-deoxy$\left[{ }^{3} \mathrm{H}\right]$ glucose (2-DG, $150 \mu \mathrm{Ci} / \mathrm{kg}$; Amersham, Los Angeles, CA) mixed with $20 \%$ glucose $(2 \mathrm{~g} / \mathrm{kg})$. Blood samples were extracted at 0, 15, 30, 60 min to measure blood glucose and glucose-specific activity. After $120 \mathrm{~min}$, the mice were killed, and $100 \mathrm{mg}$ of tissues were homogenized in $1 \mathrm{~mL}$ of water. Seven percent ice-cold perchloric acid $(800 \mu \mathrm{L})$ was added to homogenate $(800 \mu \mathrm{L})$. The sample was then cleared by centrifugation, and $1 \mathrm{~mL}$ of the supernatant was neutralized for $30 \mathrm{~min}$ with $2.2 \mathrm{~mol} / \mathrm{L} \mathrm{HCO}_{3}$. The precipitate was removed by centrifugation, and 500 $\mu \mathrm{L}$ of the supernatant was used to determine total ${ }^{3} \mathrm{H}$ radioactivity.

\section{C-fos and BMP9 immunohistochemistry (IHC)}

On day 7 of ICV Ad-BMP9 or Ad-GFP injection, animals were anesthetized and perfused with saline/heparin (20 $\mathrm{U} / \mathrm{mL}$ ) for $3 \mathrm{~min}$ and then with $4 \%$ paraformaldehyde/PBS $(0.1 \mathrm{~mol} / \mathrm{L})$ for $20 \mathrm{~min}$. The hypothalamus was excised and transferred to $4 \%$ paraformaldehyde, finally, fixed at $4^{\circ} \mathrm{C}$ for $24 \mathrm{~h}$. After being dehydrated with ethanol and xylene, the specimens were embedded in paraffin, and coronal sections of the hypothalamus were obtained. IHC for c-Fos (1:200, Abcam Cat\# ab71809, RRID: AB_2737414) and BMP9 (Abcam Cat\# ab71809, RRID: AB_1267808) were performed as previously reported (Wu et al. 2014).

\section{Analysis of phosphatidylinositol 3,4,5-trisphosphate (PIP3) formation in situ}

PIP3 formation was carried out using a fluoresceinconjugated Anti-PIP3 (Echelon Biosciences Cat\# Z-G345, RRID: AB_427218) as reported previously (Könner et al.
2007). For the quantitative analysis of PIP3, three coronal sections of the arcuate nucleus (ARC) in each mouse at bregma $1.3,1.4$ and $1.5 \mathrm{~mm}$ were examined including 600-800 cells. The percentage of positively stained ARC cells was presented as PIP3 levels. Image J software was used to score the positively stained area, which was presented as PIP3 formation.

\section{Analysis of real-time quantitative PCR and Western blot}

Mice were anesthetized using $\mathrm{CO}_{2}$ and were decapitated. Brains were removed immediately and the hypothalamus was isolated, frozen in liquid nitrogen and kept at $-160^{\circ} \mathrm{C}$ until processed for total RNA and protein extraction (Sahu et al. 2017). RT-PCR was performed as described previously (Wu et al. 2014). The primer pairs used for RT-PCR experiments were listed in Supplementary Table 1 (see section on supplementary materials given at the end of this article). Primary antibodies used for Western blot detection included anti-insulin receptor (InsR) (Cell Signaling Technology Cat\# 3025, RRID:AB_2280448)/ anti-phospho-InsR (Cell Signaling Technology Cat\# 3024, RRID:AB_331253), anti-AKT kinase (AKT) (Cell Signaling Technology Cat\# 9272, RRID:AB_329827)/antiphospho-AKT (Cell Signaling Technology Cat\# 9271, RRID:AB_329825), anti-mammalian target of rapamycin (mTOR) (Cell Signaling Technology Cat\# 2972, RRID:AB_330978)/anti-phospho-mTOR (Cell Signaling Technology Cat\# 2971, RRID:AB_330970), and anti-p70 ribosomal S6 kinase (p70S6k) (Cell Signaling Technology Cat\# 9202, RRID:AB_331676)/anti-phospho-p70S6k (Cell Signaling Technology Cat\# 9204, RRID:AB_2265913), antiglucose-6-phosphatase (G6Pase) (Abcam Cat\# ab83690, RRID:AB_1860503), anti-BMP9 (Abcam Cat\# ab71809, RRID:AB_1267808), anti-phosphoenolpyruvatecarboxykinase (PEPCK) (Santa Cruz Biotechnology Cat\# sc-32879, RRID:AB_2160168) and $\beta$-actin (Cell Signaling Technology Cat\# 4970, RRID:AB_2223172). In addition, anti-BMP9 was identified (Supplementary Fig. 1).

\section{Analytical procedures}

$\left[3-{ }^{3} \mathrm{H}\right]$ Glucose and 2-DG radioactivities were determined by the scintillation counter. Serum-free fatty acid (FFA) was measured spectrophotometrically using a commercial kit. An ELISA kit was used to measure serum insulin levels. Serum aspartate transaminase (AST) and alanine transaminase (ALT) were measured by an auto-analyzer (Hitachi High-Technologies Corp.). 


\section{Statistical analyses}

Data were presented as mean \pm s.e. A two-way ANOVA with a least significant difference post hoc test was used to compare mean values between multiple groups, and a two-sample paired, or unpaired Student's $t$-test was used for comparison between two groups. Energy expenditure was analyzed by ANCOVA (Tschöp et al. 2011). $P<0.05$ was considered significant.

\section{Results}

\section{BMP9 expression and distribution of GFP in the hypothalamus of mice}

First, we analyzed BMP9 mRNA expression using RT-PCR and found that BMP9 was highly expressed in the hypothalamus, but hardly in the kidney (Supplementary Fig. 2). To explore whether hypothalamic BMP9 expression was altered under IR state, its expression level was determined in $\mathrm{db} / \mathrm{db}$ mice, and NCD- or HFD-fed WT and Adipoq $^{-/-}$mice. We found that the levels of BMP9 protein were markedly decreased in the hypothalamic tissues of $\mathrm{db} / \mathrm{db}$ mice (Fig. 1A), HFD-fed WT and Adipoq ${ }^{-/-}$mice (Fig. 1B and Supplementary Fig. 3A) compared to those in NCD-fed WT mice. In addition, the levels of BMP9 protein in HFD-fed Adipoq ${ }^{-/-}$mice were also markedly lower than those in NCD-fed WT and Adipoq ${ }^{-/-}$mice (Fig. 1B). These data indicated a possible involvement of hypothalamic BMP9 in genetic- and environmentalinduced IR. To examine the anatomical distribution of the viral vector post-ICV injection, we used spectral confocal microscopy to evaluate GFP expression (green) in the brain. As shown in Fig. 1C, the results demonstrated that GFP was mainly expressed in the hypothalamic region. In addition, IHC staining of BMP-9 protein expression was shown in Fig. 1D.

\section{Effect of ICV Ad-BMP9 on hypothalamic BMP9 expression and energy expenditure}

To assess the impact of ICV injection of Ad-BMP9 on hypothalamic BMP9 expression in mice, we performed Western blot analyses. As shown in Fig. 2A and Supplementary Fig. 3B, treatment with central Ad-BMP9 resulted in increased BMP9 protein levels in the hypothalamus of both NCD- and HFD-fed mice. In addition, ICV Ad-BMP9 treatment of HFD-fed mice resulted in an increase in the number of Fos-positive cells in the ARC, paraventricular (PVN), and dorsomedial nucleus (DMN), which are involved in energy balance (Fig. 2B). The serum levels of total cholesterol, triglyceride, FBG, insulin, and FFA were similar between Ad-BMP9- and Ad-GFP-treated mice fed an NCD (Supplementary Table 2). In HFD mice, however, ICV Ad-BMP9 treatment led to a significant reduction in insulin, total cholesterol, triglyceride, and FFA levels compared with Ad-GFP treatment (Supplementary Table 2). Subsequently, we investigated the impact of ICV Ad-BMP9 treatment on energy expenditure. The results showed that, under HFD feeding, Ad-BMP9-treated mice displayed an increase in rectal temperature (Fig. 2C), and decrease in body weight (Fig. 2D and E), fat mass (Supplementary Fig. 4A), food intake (Fig. 2F), feeding blood glucose (Fig. 2G), and blood pressure (Fig. $2 \mathrm{H}$ ) compared with Ad-GFPtreated mice. These results also suggest that the effects of BMP9 overexpression on food intake and body weight may not be due to virus delivery, as shown in NCDfed mice. Furthermore, we used indirect calorimetry to measure energy expenditure in NCD- and HFD-fed mice treated with Ad-BMP9 or Ad-GFP. We found that under HFD conditions, ICV Ad-BMP9-treated mice exhibited markedly increased $\mathrm{VO}_{2}$ (Fig. 2I), $\mathrm{CO}_{2}$ production (Fig. 2J), and heat (Fig. 2L), and decreased RER (Fig. 2K) compared with Ad-GFP-treated mice. Furthermore, the relationship between energy expenditure and body weight were analyzed by ANCOVA in these mice (Fig. 2M). These results demonstrated that ICV Ad-BMP9 reduced body weight in HFD-fed mice by elevating energy expenditure.

\section{Overexpression of BMP9 in the mediobasal hypothalamus enhances glucose metabolism in HFD-fed mice}

To investigate the glycoregulatory effects of ICV administration of Ad-BMP9, we first examined whether overexpression of hypothalamic BMP9 is sufficient to alter glucose kinetics in vivo. Ad-BMP9-treated HFD-fed mice showed significantly increased glucose tolerance and clearance, as indicated by the results of GTT and ITT, respectively, compared with Ad-GFP-treated mice (Fig. $3 \mathrm{~A}$ and $\mathrm{B})$. In addition, GTT in HFD fed mice was similar on the third day of Ad-GFP and Ad-BMP9 treatment (Supplementary Fig. 4B).

Next, we assessed the impact of Ad-BMP9 treatment on glucose turnover by HEC in NCD- or HFD-fed mice (Fig. 3C). During HEC, the serum parameters used are shown in Supplementary Table 3. Blood glucose was clamped at $4.5-6 \mathrm{mM}$ and insulin levels were raised to $\sim$ four-fold the basal value. The time courses of blood glucose and 
A

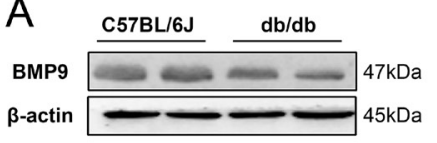

$\mathrm{C}$
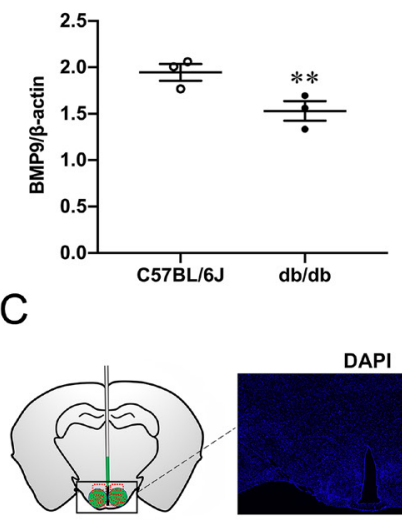

Above the hypothalamus
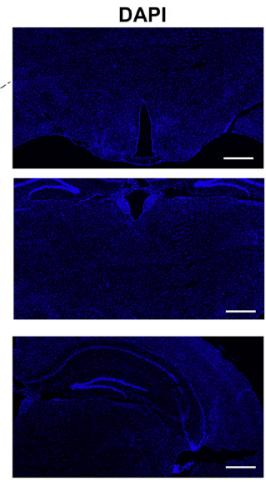

hippocampus
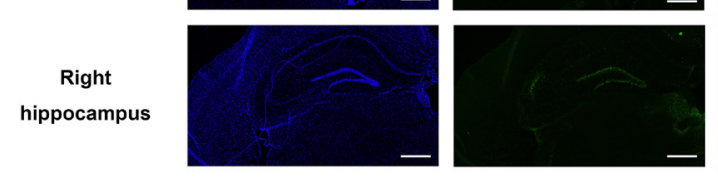

D

Ad-GFP
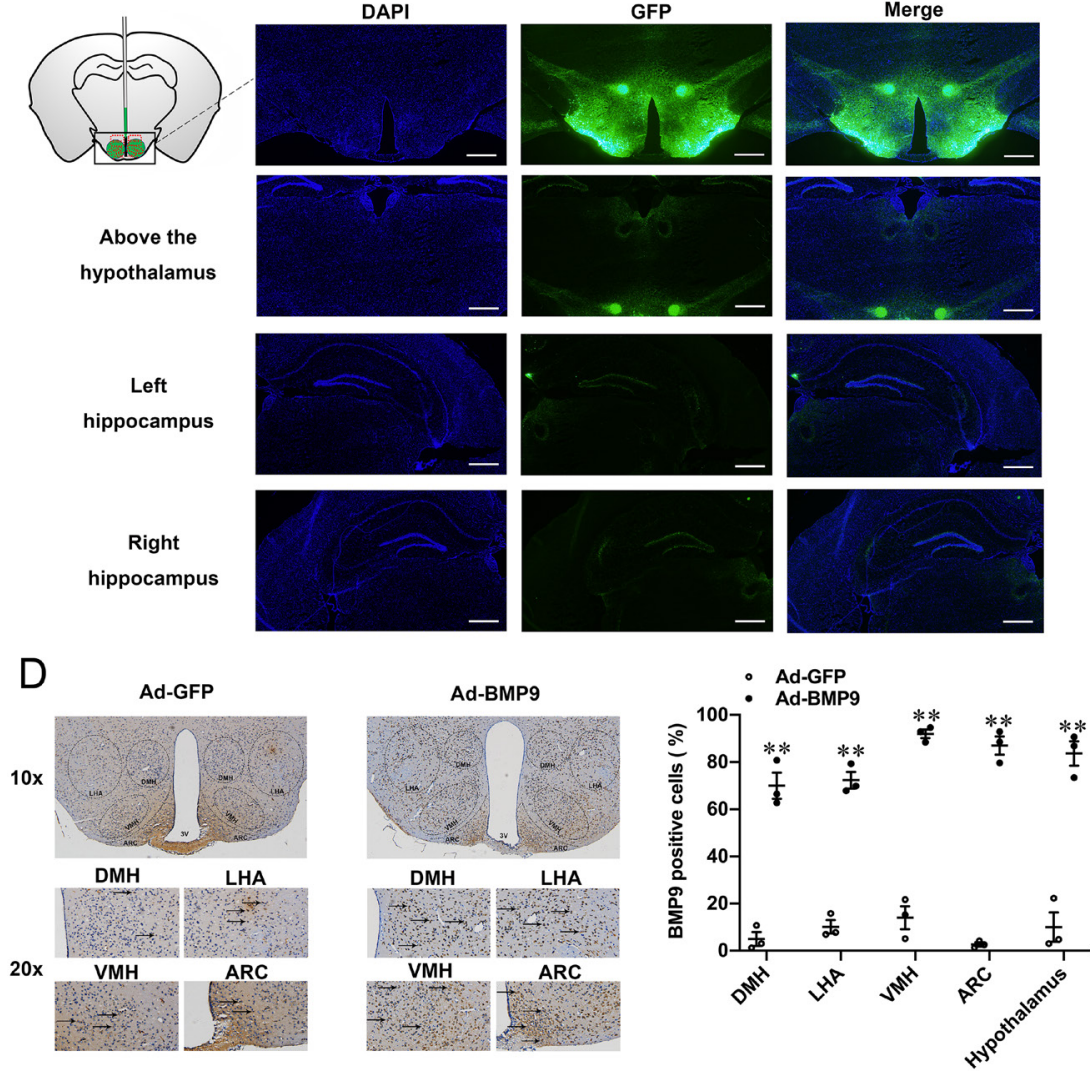

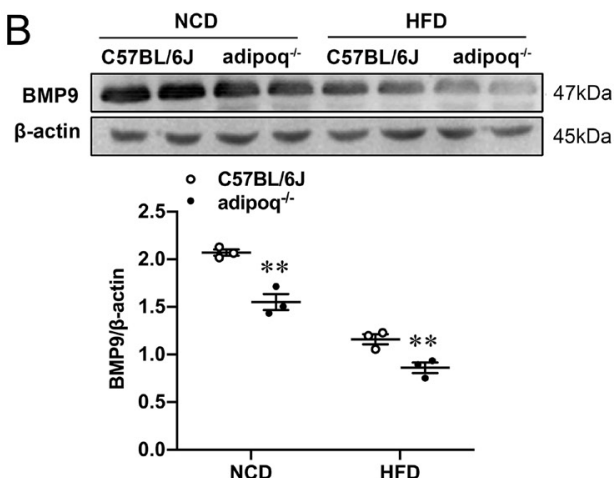

\section{Figure 1}

BMP9 expression and distribution of GFP in the hypothalamus of mice. (A) BMP9 protein expression in the hypothalamus of $\mathrm{C} 57 \mathrm{BL} / 6 \mathrm{~J}$ and $\mathrm{db} / \mathrm{db}$ mice. (B) BMP9 protein expression in the hypothalamus of NCD- or HFD-fed C57BL/6] and Adipoq $^{-/-}$mice. (C) Frontal sections of the brain for expression region of the fluorescent reporter GFP (green). (D) Immunohistochemical staining for BMP-9 expression in the hypothalamus. Data are expressed as mean \pm S.E. NCD, normal chow diet; HFD, high-fat diet; Adipoq, adiponectin. The data are expressed as the mean \pm S.E. $(n=3 /$ group). ${ }^{*} P<0.01$ compared with C57BL/6] mice. glucose infusion rate (GIR) during HEC were shown in Supplementary Fig. 5A and B. During the steady-state of HEC, compared to Ad-GFP, Ad-BMP9 treatment did not affect the ability of insulin to increase GIR (Fig. 3D) and inhibit hepatic glucose production (HGP) in NCD mice (Fig. 3E and F). However, in HFD-fed mice, Ad-BMP9 treatment significantly elevated the GIR required to prevent hypoglycemia (Fig. 3D) and lowered HGP (Fig. $3 \mathrm{E}$ and F) during the clamps, as compared to Ad-GFP treatment. Under the HFD condition, the rate of glucose disappearance (GRd) was also elevated in Ad-BMP9treated mice compared with that in Ad-GFP-treated mice (Fig. 3G). To determine the impact of ICV Ad-BMP9 on insulin-induced peripheral glucose utilization, tissuespecific sensitivity to insulin was determined in vivo by measuring 2-DG uptake in the WAT and skeletal muscle. Glucose uptake in the WAT of NCD- and HFD-fed mice was comparable between the Ad-BMP9 and Ad-GFP treatment groups (Fig. $3 \mathrm{H}$ ). However, in the skeletal muscle of HFDfed mice, Ad-BMP9 treatment induced a $20 \%$ increase in glucose uptake compared to Ad-GFP treatment (Fig. 3I). These results indicate that central BMP9 overexpression in HFD-fed IR mice improves hepatic and peripheral insulin action. However, we cannot exclude the BMP9-mediated effects on glucose metabolism may be secondary to weight loss. 

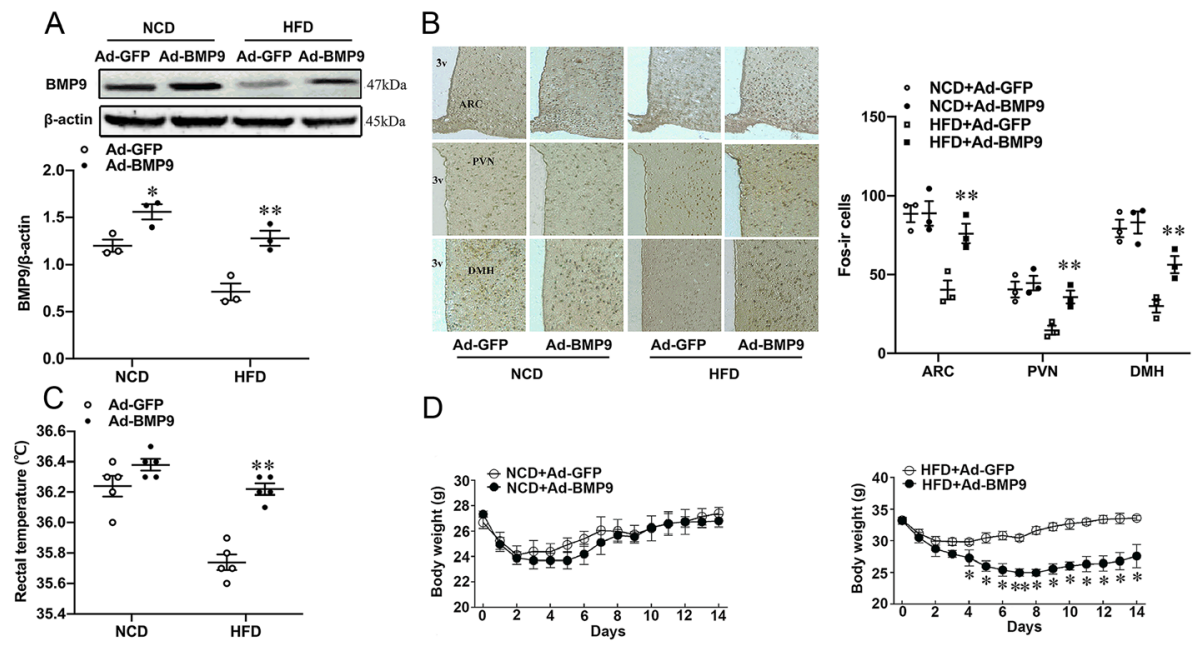

D
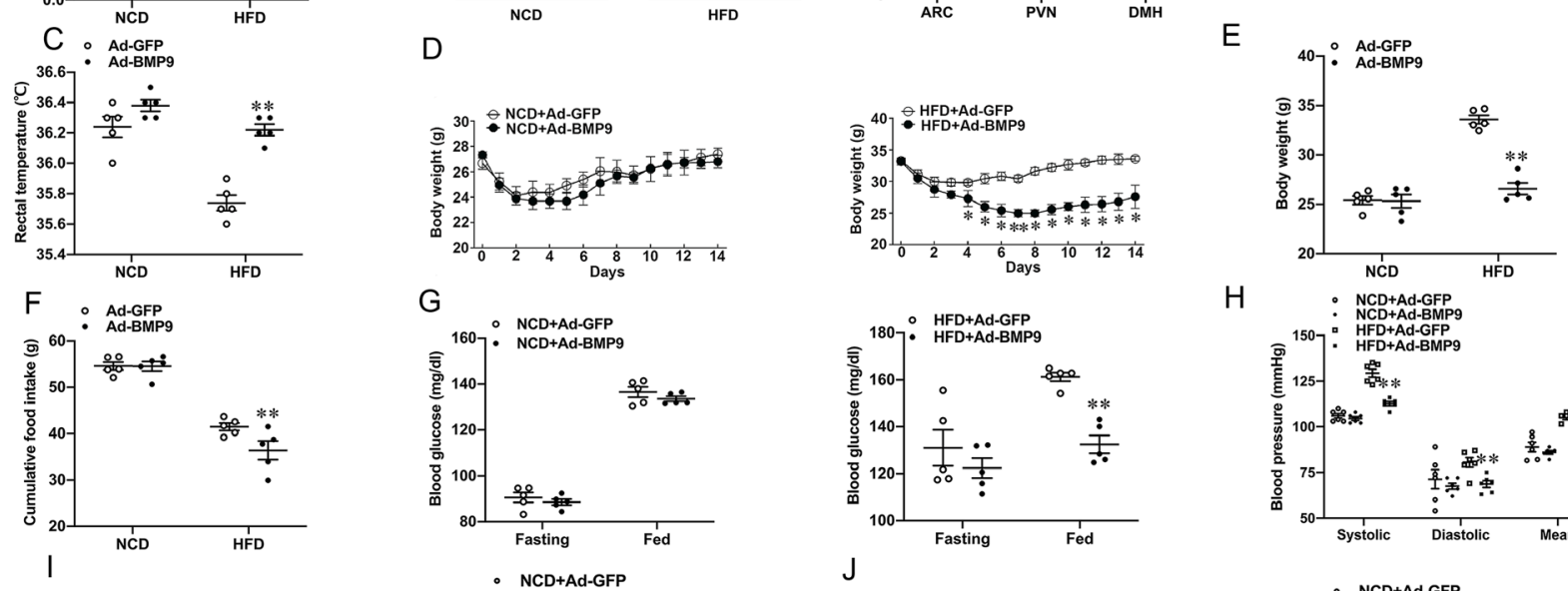

$\mathrm{H}$
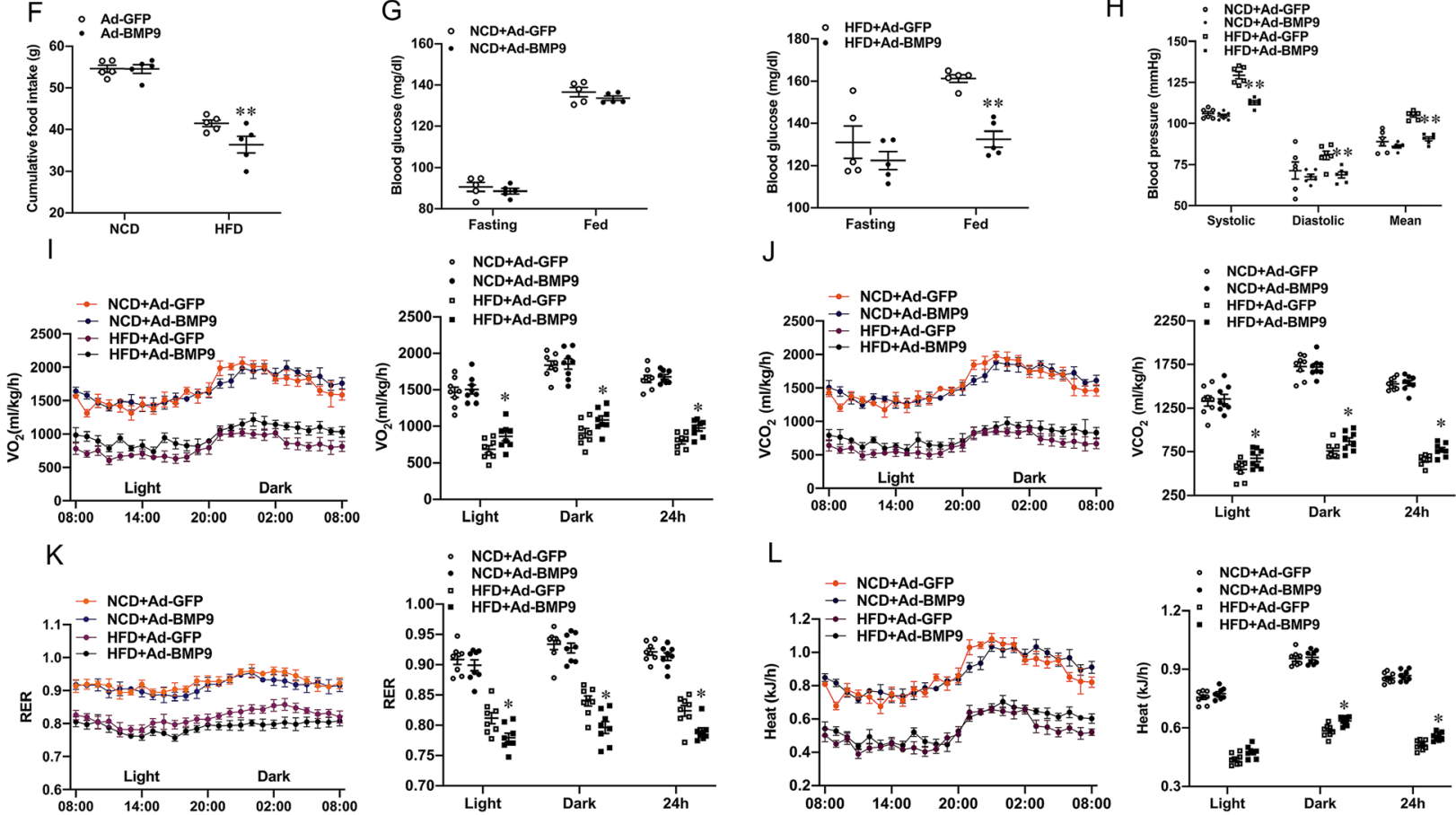

L
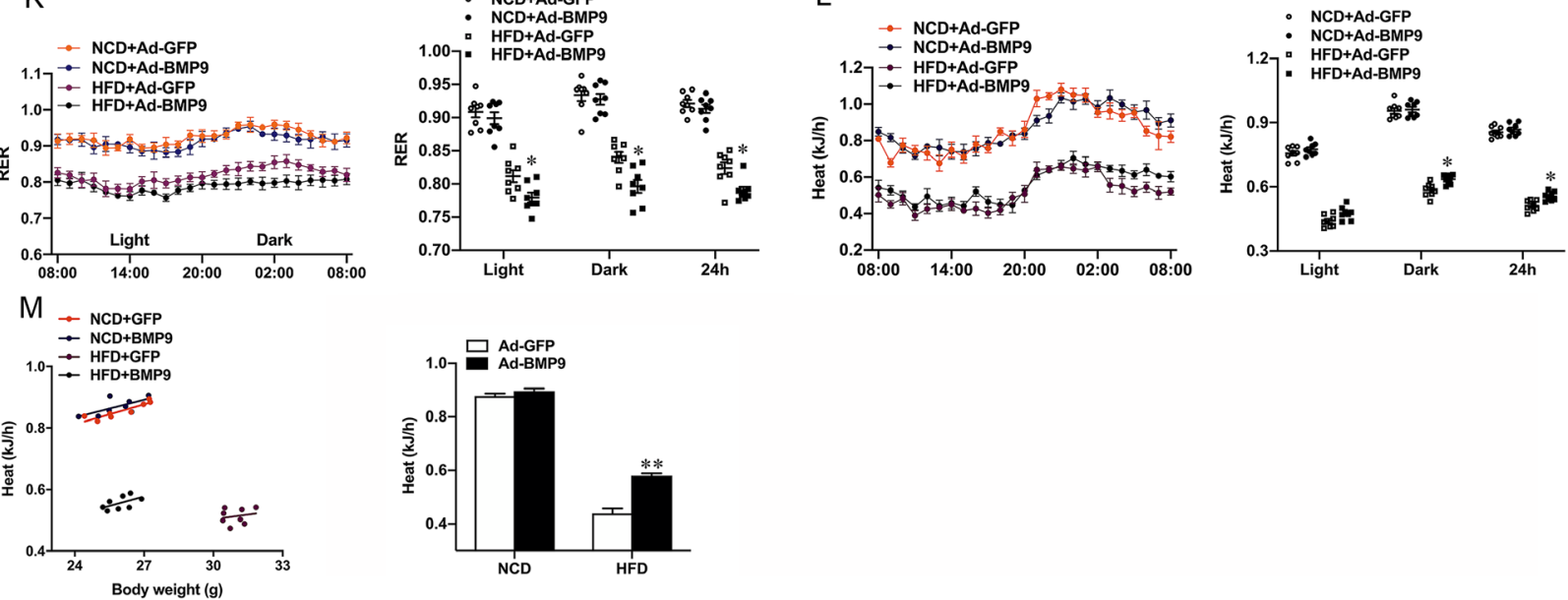

Figure 2

Overexpression of hypothalamic BMP9 increases energy expenditure in HFD-induced obesity and insulin resistance. Mice received intracerebroventricular (ICV) injection of adenovirus expressing BMP9 (Ad-BMP9) or green fluorescent protein (Ad-GFP) prior to all measurements on day 7 post-adenoviral injection. (A) BMP9 protein expression in the hypothalamus. (B) Fos immunoreactivity (ir) in hypothalamic regions, including the arcuate (ARC), paraventricular, and dorsomedial nucleus, in ICV Ad-BMP9 or vehicle-treated mice. Left panel: photomicrographs of coronal brain sections; right panel: number of Fos-ir cells per section. (C) Rectal temperature. (D) Body weight for 2 weeks. (E) Body weight changing. (F) Food intake for 2 weeks. (G) Blood glucose levels. (H) Blood pressure. (I) 24-h oxygen consumption. (I) 24-h $\mathrm{CO}_{2}$ production $\left(\mathrm{VO}_{2}\right)$. (K) Respiratory exchange ratio (RER: $\left.\mathrm{V}_{\mathrm{C}} \mathrm{O}_{2} / \mathrm{V}_{\mathrm{O} 2}\right)$. (L) Energy expenditure. (M) Energy expenditure per mouse was plotted against body weight (left panel) and the adjusted means of energy expenditure (right panel) analyzed by ANCOVA. The data are expressed as the mean \pm S.E. (Western blot: $n=3$ /group; animal experiments: $n=5-8 /$ group). NCD, normal chow diet; HFD, high-fat diet. $* P<0.05 ; * * P<0.01$ vs Ad- GFP. 
A

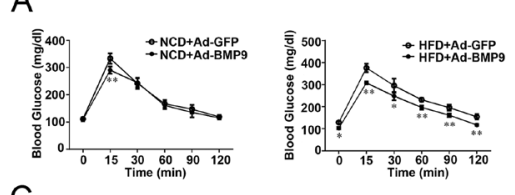

C

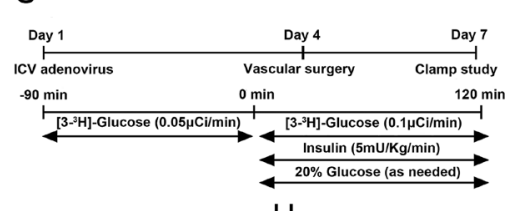

$\mathrm{H}$
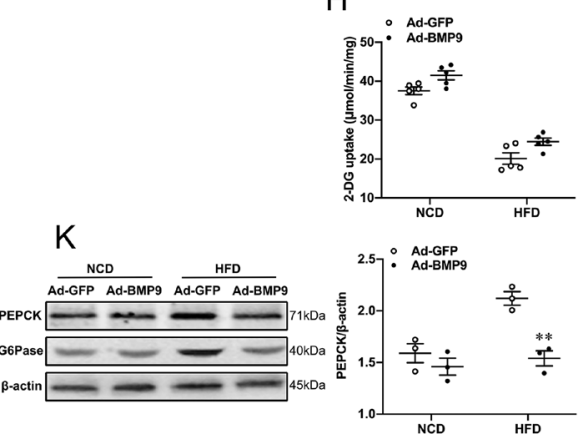

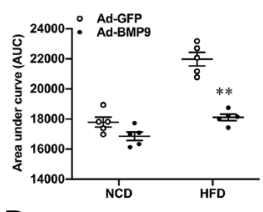

D

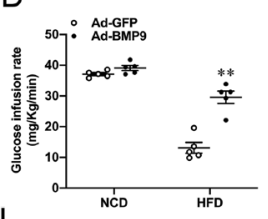

1 Ad AdGPP
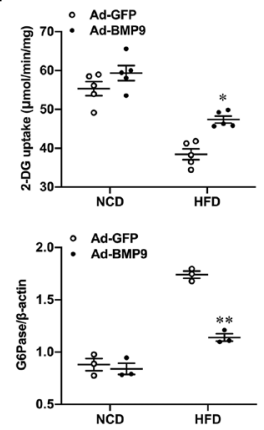

B

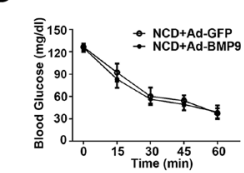

E
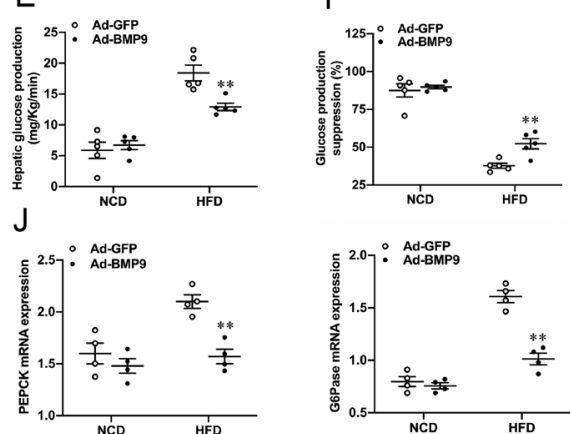

$\mathrm{L}$

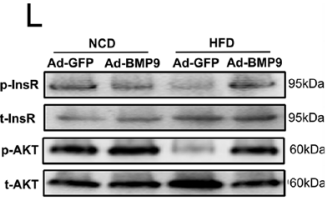

$\mathrm{F}$

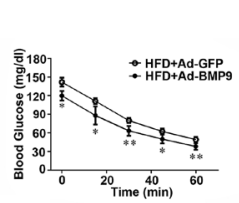

告)

G
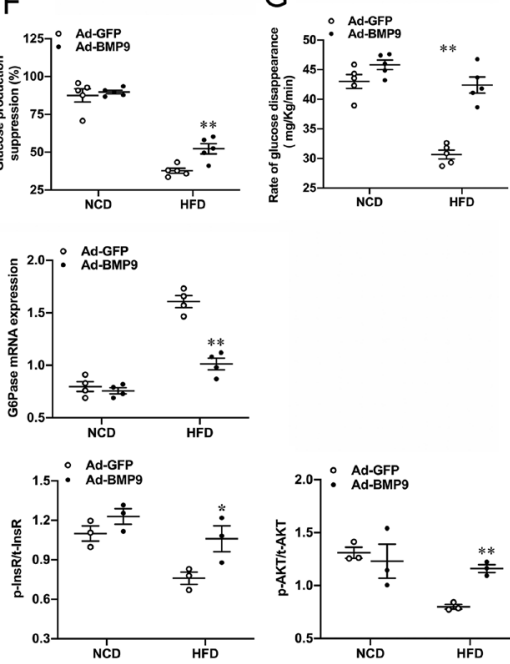

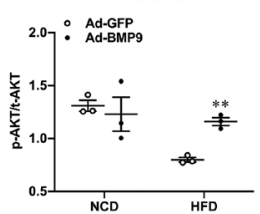

Figure 3

Activation of hypothalamic BMP9 by ICV injection of Ad-BMP9 ameliorates hepatic insulin resistance. Mice received ICV injection of adenovirus expressing BMP9 (Ad-BMP9) or green fluorescent protein (Ad-GFP) prior to all experiments on day 7 post-adenoviral injection. (A) Intraperitoneal glucose tolerance tests (GTT). (B) Insulin tolerance tests (ITT). (C) Experimental procedure and clamp protocol. (D) Glucose infusion rates (GIR). (E) Hepatic glucose production (HGP). (F) Percentage of suppression of endogenous glucose production. (G) Glucose disposal rate (GRd). (H) Rates of 2DG uptake in visceral adipose tissue. (I) Rates of 2DG uptake in skeletal muscle. () PEPCK and G6Pase mRNA expression in the liver. (K) PEPCK and G6Pase protein levels in the liver. (L) Immunoblot analysis of phospho-InsR/total InsR ratio and phospho-Akt/total Akt ratio in the liver. Data are means \pm s.E. (Western blot: $n=3$ / group; animal experiments: $n=5$-6/group). NCD, normal chow diet; HFD, high-fat diet. ${ }^{*} P<0.05$; $* * P<0.01$ vs Ad-GFP.

\section{ICV Ad-BMP9 improves hepatic IR in HFD-fed mice}

Based on the changes in glucose turnover, we examined the mRNA and protein levels of PEPCK and G6Pase, two key gluconeogenic enzymes, in the liver. In NCD-fed mice, ICV Ad-BMP9 treatment did not alter the mRNA and protein levels of hepatic G6Pase and PEPCK (Fig. 3J and $\mathrm{K})$. As expected, HFD feeding increased the mRNA and protein levels of hepatic G6Pase and PEPCK compared to NCD feeding. However, in HFD-fed mice, ICV Ad-BMP9 treatment significantly decreased the mRNA and protein levels of the two gluconeogenic genes in the liver, as compared with Ad-GFP treatment (Fig. 3J and K). Next, we investigated the impact of ICV injection of Ad-BMP9 on hepatic insulin signaling. As shown in Fig. 3L, HFD feeding decreased InsR and AKT phosphorylation in the liver. However, overexpression of hypothalamic BMP9 under HFD condition significantly enhanced insulinstimulated phosphorylation of InsR and AKT in the liver, as compared with the control group (Fig. 3L).

\section{ICV Ad-BMP9 increases anorexigenic neuropeptide expression and enhances insulin sensitivity via the InsR-PI3K-Akt dependent pathway in HFD-fed mice}

Next, we used quantitative RT-PCR to analyze the expression of hypothalamic proopiomelanocortin (POMC), an anorexigenic neuropeptide, and agoutirelated peptide (AgRP) and neuropeptide $\mathrm{Y}$ (NPY), two orexigenic peptides. In NCD-fed mice, Ad-BMP9 treatment did not alter the expression of NPY, POMC, and AgPR mRNA in the hypothalamus of mice (Fig. 4A). However, under the HFD condition, Ad-BMP9 treatment led to a reduction of NPY expression and an increase of POMC expression in the hypothalamus as compared with Ad-GFP treatment (Fig. 4A). We further investigated whether Ad-BMP9 treatment affected insulin signaling in the hypothalamus of mice. Under NCD condition, the levels of hypothalamic InsR and AKT phosphorylation, in response to insulin, were not different between Ad-BMP9and vehicle-treated mice (Fig. 4B). However, under the 

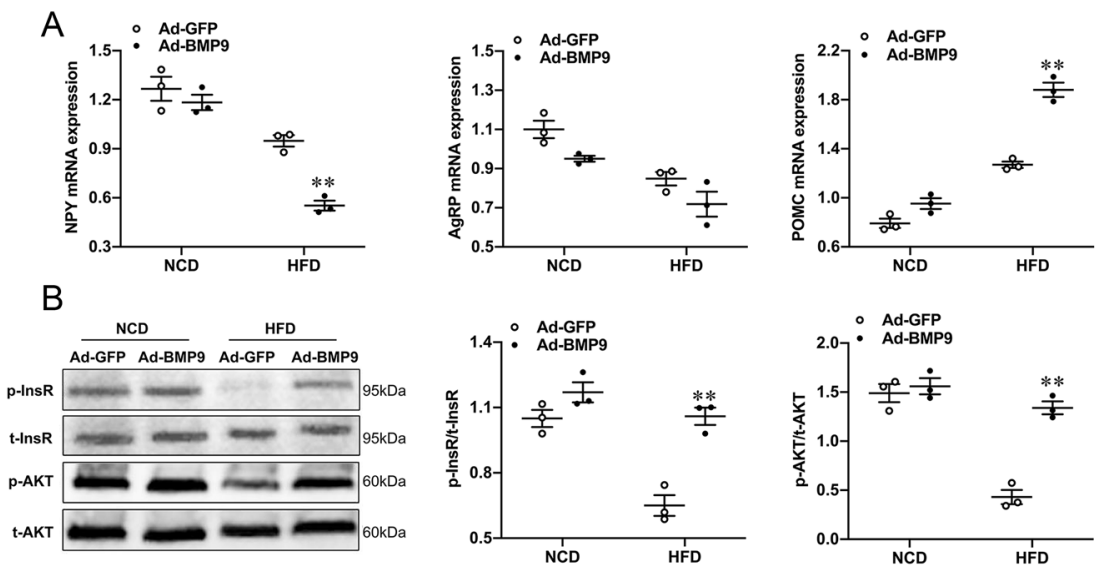

\section{C}
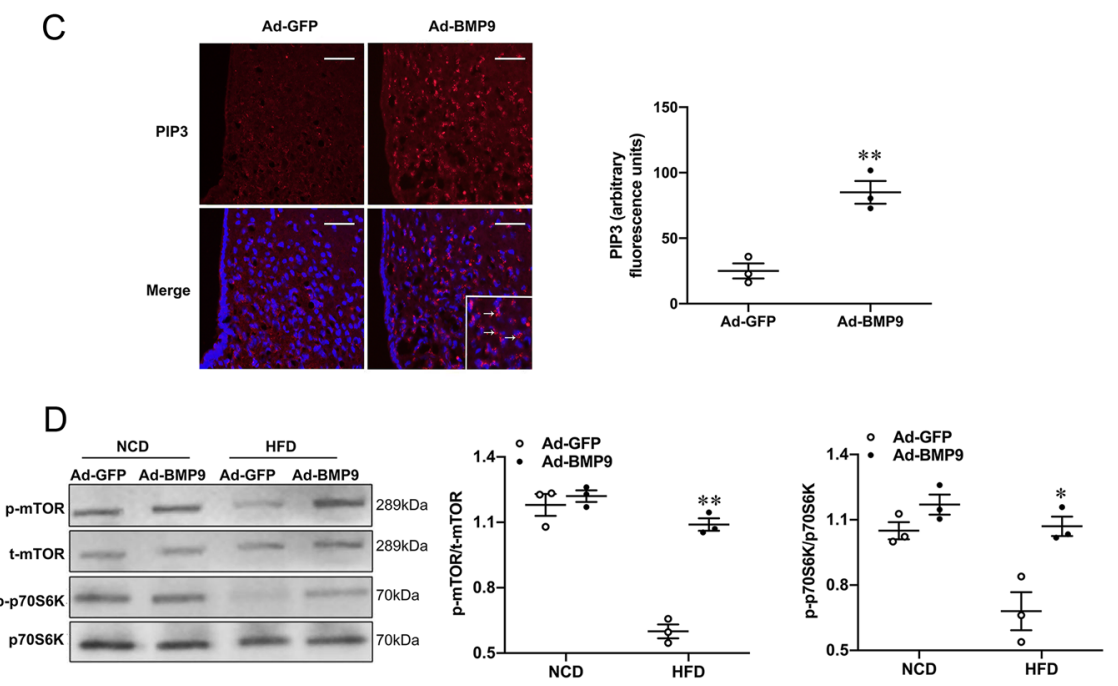

\section{Figure 4}

Activation of hypothalamic BMP9 ameliorates central insulin sensitivity. Mice received ICV injection of adenovirus expressing BMP9 (Ad-BMP9) or green fluorescent protein (Ad-GFP) prior to all experiments on day 7 post-adenoviral injection. (A) The mRNA expressions of NPY, agouti-related peptide, and POMC in the hypothalamus. (B) Immunoblot analysis of phospho-InsR/total InsR ratio and phospho-Akt/ total Akt ratio in the hypothalamus. (C) Immunofluorescence for PIP3 formation (left panels) and quantification of PIP3 levels (right panels) in ARC sections. Short arrows indicate PIP3 formation. (D) Phosphorylation of mTOR/7S6K1 in the hypothalamus (left, Western blot; right, quantitative measurement of protein). Data are means \pm S.E. (Western blot: $n=3 /$ group; animal experiments: $n=5$-6/group). NCD, normal chow diet; HFD, high-fat diet. $* P<0.05$; $* * P<0.01$ vs Ad-GFP.
HFD condition, InsR and AKT phosphorylation in the hypothalamus was lower than that in the NCD condition. Importantly, ICV Ad-BMP9 treatment in HFD-fed mice led to an increase in InsR and AKT phosphorylation in the hypothalamus compared to vehicle treatment (Fig. 4B).

To investigate whether the major downstream pathway of InsR was activated by ICV injection of Ad-BMP9, we assessed the impact of hypothalamic Ad-BMP9 on the ability of insulin to promote PIP3 formation in the hypothalamic neurons of HFD-fed mice. Immunofluorescence staining showed that PIP3 formation in the ARC was increased in Ad-BMP9-treated mice (Fig. $4 C)$. These data suggest that Ad-BMP9 treatment increases the ability of insulin to activate the PIP3 kinase pathway.

\section{Inhibition of hypothalamic mTOR/S6K pathway reverses the ability of ICV Ad-BMP9 to regulate HGP and insulin signaling}

To map the signaling pathways by which BMP9 regulates peripheral metabolic events, we performed
ICV injection of Ad-BMP9 and evaluated the activation of potential signaling candidates by western blot analysis. Consistent with previous reports (Ono et al. 2008), HFD-feeding significantly reduced mTOR and p70S6k phosphorylation in the hypothalamus of mice (Fig. 4D). However, ICV Ad-BMP9 treatment markedly increased the phosphorylation of mTOR and S6K1 in the hypothalamus of HFD-fed mice compared with Ad-GFP treatment (Fig. 4D). Finally, to elucidate the functional significance of BMP9-mediated mTOR activation in the regulation of glucose metabolism, Ad-BMP9- or Ad-GFPtreated HFD-fed mice were subjected to ICV injection of rapamycin, an inhibitor of mTOR complex 1 (p70S6K) signaling. The results showed that rapamycin treatment almost completely abolished BMP9-induced mTOR and p70S6K phosphorylation in the hypothalamus (Fig. 5A). Consistent with results obtained in the hypothalamus, rapamycin treatment largely reversed Ad-BMP9-induced improvement in glucose tolerance and clearance (Fig. 5B and $\mathrm{C}$ ). Accordingly, rapamycin treatment also abolished the effects of ICV Ad-BMP9 on the mRNA (Fig. 5D) and 

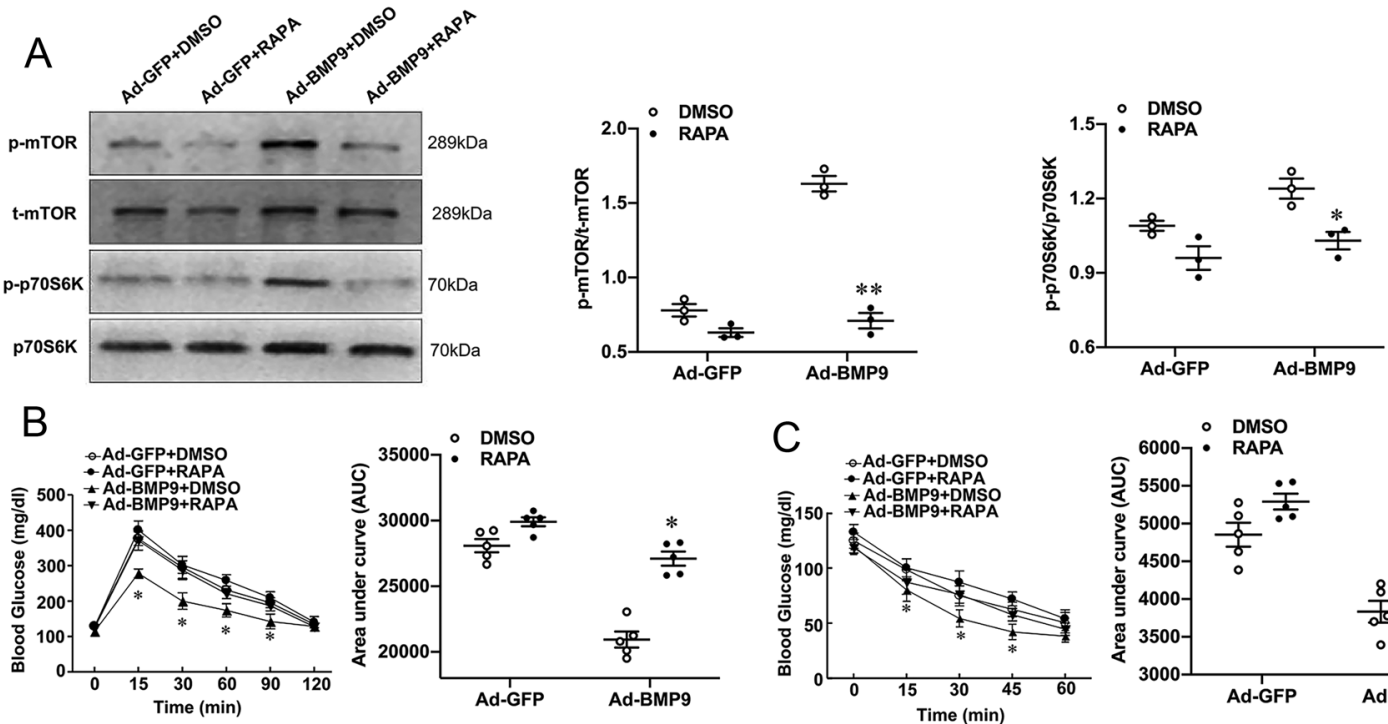

C
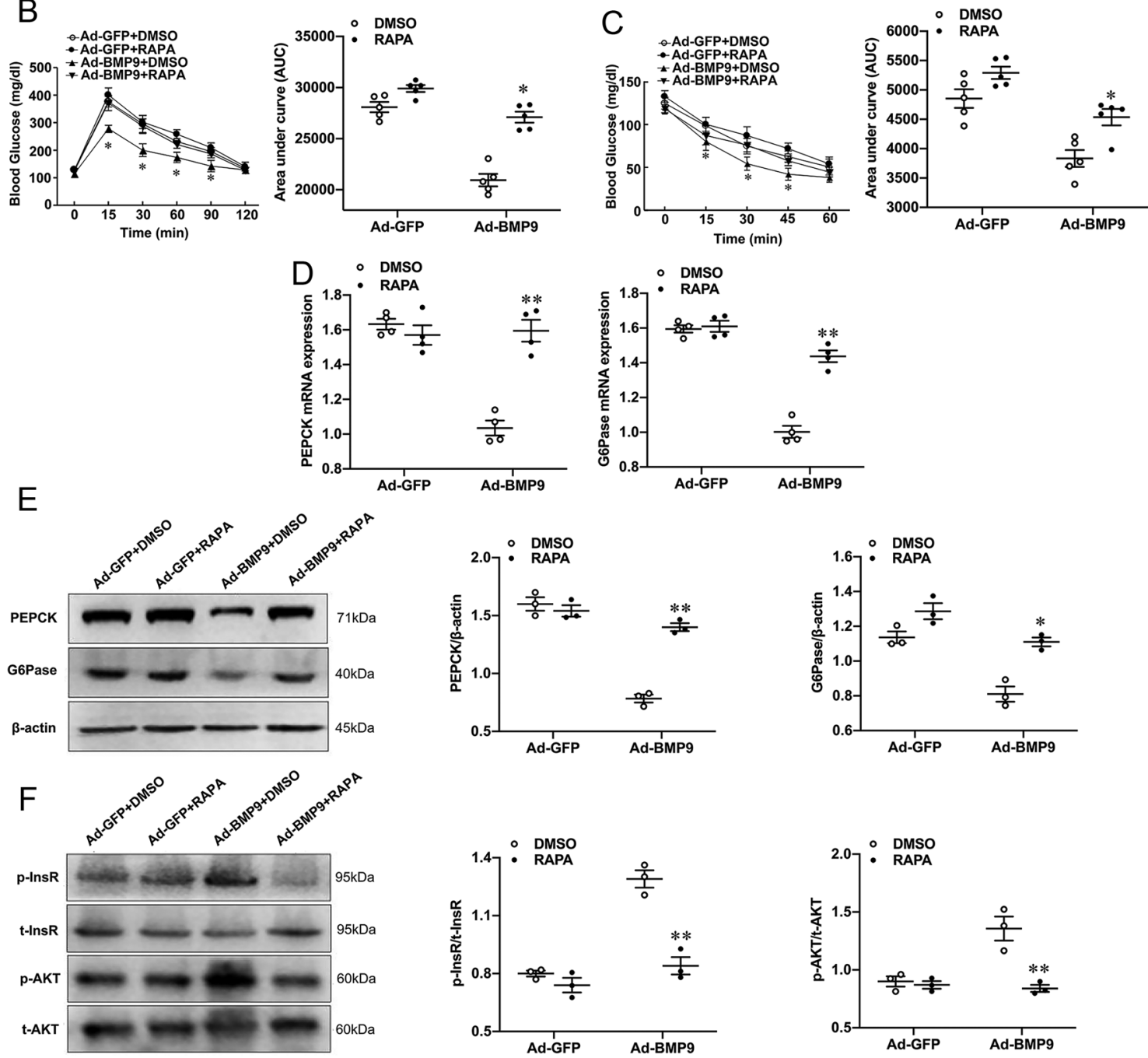

Figure 5

Inhibition of hypothalamic mTOR by ICV injection of rapamycin reverses the increase of hepatic insulin sensitivity induced by hypothalamic BMP9. HFD-fed mice received ICV injection of adenovirus expressing BMP9 (Ad-BMP9) or green fluorescent protein (Ad-GFP) prior to all experiments on day 7 post-adenoviral injection. Rapamycin or DMSO was injected into ICV $3 \mathrm{~h}$ before the experiment. (A) Phosphorylation of mTOR/70S6K1 in the hypothalamus (left, Western blot; right, quantitative measurement of protein). (B) Intraperitoneal glucose tolerance tests (GTT). (C) Insulin tolerance tests (ITT). (D) PEPCK and G6Pase mRNA expression in the liver. (E) PEPCK and G6Pase protein levels in the liver. (F) Immunoblot analysis of phospho-InsR/total InsR and phospho-Akt/total Akt ratio in the liver. Data are means \pm S.E. (Western blot: $n=3$ /group; animal experiments: $n=5-6 /$ group). * $P<0.05$; $\star \star P<0.01$ vs DMSO. 
protein (Fig. 5E) expression of gluconeogenic genes and insulin signaling (Fig. 5F) in the liver.

\section{Hepatic innervation is required to mediate the effect of ICV Ad-BMP9 on glucose metabolism}

To further explore the pathway that mediates the impact of BMP9 on glucose metabolism, we performed HVG or sham operation in Ad-GFP- or Ad-BMP9-treated HFD-fed mice. As showed in Supplementary Fig. 6A. there were no significant changes in body weight and food intake 6 days before virus injection in the HVG and SHAM groups. However, HVG completely eliminated the effects of ICV Ad-BMP9 on body weight and food intake (Supplementary Fig. 6A). Results of GTT and ITT showed that, in sham mice, ICV Ad-BMP9 treatment significantly lowered blood glucose level and the glucose area under the curve (AUC) compared to Ad-GFP treatment. However, in HVG mice, the effects of Ad-BMP9 on blood glucose were attenuated, as shown by GTT and ITT (Supplementary Fig. 6B and C). These results suggest that vagal innervation is required for mediating the effect of BMP9 on glucose metabolism.

\section{Discussion}

In the current study, our data demonstrate that: (1) hypothalamic BMP9 expression is downregulated in insulin-resistant animals, (2) overexpression of hypothalamic BMP9 increases energy expenditure, decreases body weight, and food intake, (3) ICV administration of Ad-BMP9 diminishes HGP and reinforces hepatic insulin action, (4) Ad-BMP9 enhances insulin sensitivity via the InsR/PI3k/Akt pathway in the hypothalamus, and (5) mTOR/S6K signaling is essential for mediating the effect of hypothalamic BMP9 on glycoregulation and insulin action. These findings reveal the central role of BMP9 in the regulation of energy equilibrium and insulin sensitivity in vivo.

As in our previous study and other publications (Contreras et al. 2014, Wu et al. 2014, Quaresma et al. 2017), in this study, we performed stereotaxic injection of a viral vector for gene manipulation in the ICV to build an adult-onset overexpression of BMP9 in the hypothalamus. In recent years, stereotaxic injection of a viral vector has become an indispensable tool that allows scientists to functionally dissect the roles of hormones and neural circuits in vivo (Nectow et al. 2017). However, one limitation of this study is that an adenoviral infection may cause brain inflammation, thereby complicating data interpretation. We used a GFP-expressing adenovirus as a control to address this problem. Another limitation of this study is that ICV injection was performed, and therefore, the nucleus specificity was lost. However, similar to previous studies (Inquimbert et al. 2013, de Moura et al. 2016, Barahona et al. 2018), we found that after ICV injection with Ad-GFP or Ad-BMP9, GFP was mainly distributed in the hypothalamus, while IHC staining showed that BMP-9 was expressed in hypothalamic nuclei related to metabolisms, such as the VMH and ARC. Thus, we believe that these results can enhance our understanding of BMP9 signaling in the CNS.

Notably, a previous study has reported that the ICV administration of BMP7 in mice leads to an acute decrease in food intake and an increase in energy expenditure (Townsend et al. 2012). In addition, another study also found that hypothalamic BMP8B increased thermogenesis, food intake, and weight loss via regulation of the hypothalamic AMP-activated protein kinase (AMPK) pathway (Whittle et al. 2012). Therefore, these reports are reminiscent of the mechanism of action of BMP underlying the regulation of energy equilibrium in the CNS. In the present study, we not only observed that BMP9 expression in the hypothalamus was downregulated in IR state, such as in $\mathrm{db} / \mathrm{db}$, Adipoq ${ }^{-/}$, and HFD-fed mice, but also demonstrated that ICV injection of Ad-BMP9 decreased appetite and body weight, and increased energy expenditure in HFD-fed insulin-resistant mice. Thus, data from the current study suggest that BMP9 may be a target for the hypothalamic regulation of energy homeostasis and that BMP9 is a cytokine with pleiotropic functions.

Furthermore, previous reports have shown that sex affects the impact of BMPs, such as BMP8B, whose thermogenic effect is only observed in females (Whittle et al. 2012, Martins et al. 2016). In previous studies in humans, no gender differences in circulating BMP9 levels were observed (Luo et al. 2017). Thus, we used male mice for the current study. However, whether the effect of BMP9 is sexually dimorphic requires further investigation.

In recent years, several studies by our group and other groups have highlighted that the CNS plays a crucial role in the modulation of whole-body energy homeostasis (Lam et al. 2011, Zhang et al. 2013, Wu et al. 2014, Yang et al. 2017). Indeed, some hormonal and cytokine signals within the hypothalamus can regulate HGP and insulin sensitivity. In the current study, overexpression of BMP9 in the hypothalamus of insulin-resistant mice enhanced insulin-mediated inhibition of HGP via inhibition of gluconeogenic enzymes, promoted glucose uptake in 
the skeletal muscle, and increased the phosphorylation of insulin signaling molecules in the liver. Therefore, we consider that the effects of the central BMP9 signal on HGP might be multifaceted, including reduced food intake, weight loss, increasing energy consumption, and direct effects on the HGP. In addition, we found that the metabolic effects of ICV Ad-BMP9 were only seen in obese mice with IR. Therefore, it is possible that the regulatory roles of BMP9 in metabolism and insulin sensitivity are limited to obesity and IR states when BMP9 activity is impaired in the hypothalamus of mice with genetic- and diet-induced IR.

These findings further indicated that hormones and cytokines, such as BMP9 and adiponectin act in the hypothalamus to ameliorate peripheral IR, thereby proposing the need for further studies on the role of BMPs in HGP regulation. However, the molecular targets of these hormones or cytokines remain unknown. Our group and other groups have reported that hormone and cytokine signals in the hypothalamus activate $\mathrm{K}_{\mathrm{ATP}}$ channels and trigger the hepatic vagus nerves to reinforce hepatic insulin signaling and regulate hepatic glucose fluxes in vivo (Knight et al. 2011, Lam et al. 2011). However, the transmission pathways of these signals within the hypothalamus remain elusive. In addition, the effects of different hormones and cytokines on insulin sensitivity may be both temporally and mechanistically distinct. Therefore, it is crucial to investigate the pathways that mediate BMP9 signaling in the brain.

Leptin and NPY have been reported to modulate food intake and energy metabolism via activation of the InsR/PI3K/Akt signaling cascade in the hypothalamus (Kim et al. 2000, Niswender et al. 2003). Therefore, we investigated whether BMP9 action in the hypothalamus was mediated by the InsR/PI3K/Akt signaling pathway to regulate hepatic glucose fluxes.

We hypothesized that BMP9 exerts its roles in hypothalamic neurons through the InsR/PI3K/Akt signaling pathway. As expected, we found that insulinstimulated InsR and Akt phosphorylation was markedly elevated in the hypothalamus of HFD-fed mice treated with Ad-BMP9 compared to that in vehicle-treated mice. In addition, Ad-BMP9 treatment markedly increased PIP3 formation in ARC neurons compared to Ad-GFP treatment. These results suggest that BMP9 increases the ability of insulin to activate the InsR/PI3K/Akt pathway in the CNS. In an in vitro study, PIP3 was shown to directly activate $\mathrm{K}_{\text {ATP }}$ channels (Kim et al. 2000). Therefore, we speculate that BMP9 may promote insulin-stimulated phosphorylation of InsR and Akt in the hypothalamus and then activate
PI3 kinase in obese mice. Subsequently, increasing PIP3 formation leads to $\mathrm{K}_{\mathrm{ATP}}$-channel activation. Finally, the hepatic vagus is triggered, and this signal is relayed to the liver to regulate hepatic glucose fluxes.

The hypothalamic mTOR/S6K pathway has been considered to be a major pathway in the hypothalamic regulation of energy homeostasis. The importance of this signaling pathway in the modulation of food intake and glucose and lipid metabolism has been highlighted in previous reports (Cota et al. 2006, Blouet et al. 2008, Mori et al. 2009). However, previous studies have reported conflicting findings regarding the metabolic effects of the hypothalamic mTOR/S6K pathway (Cota et al. 2008, Hu et al. 2016). Therefore, the precise mechanisms underlying the regulatory roles of the mTOR/S6K pathway remain largely unknown and require further investigation. In agreement with a previous report (Ono et al. 2008), but in contrast to two other reports (Blouet et al. 2008, Cota et al. 2008), we found that HFD-feeding led to a decrease in mTOR/S6K signaling in the hypothalamus, suggesting a role of hypothalamic mTOR/S6K signaling in HFD-induced IR and obesity. However, Ad-BMP9 treatment reversed this effect, accompanied by an increase in peripheral insulin sensitivity. Importantly, the ICV injection of rapamycin, an inhibitor of mTOR, largely attenuated the effects of Ad-BMP9.

Interestingly, two previous studies have reported that the effect of BMP8B on BAT thermogenesis is mediated by hypothalamic AMPK (Whittle et al. 2012, Martins et al. 2016). In the current study, we found that the effect of BMP9 on energy homeostasis in the hypothalamus was mediated by the mTOR pathway. Notably, previous studies have shown that AMPK inhibits mTORC1 both indirectly, through the phosphorylation and activation of the tuberous sclerosis complex 2, and directly, through the phosphorylation of Raptor. Therefore, AMPK may be an upstream regulator of mTOR signaling (Saxton \& Sabatini 2017). We speculate that since the thermogenic effect of BMP8B is mediated by inhibition of hypothalamic AMPK, the effect of BMP9 on energy homeostasis may also be mediated by inhibition of AMPK, facilitating the activation of the hypothalamic mTOR pathway. However, further studies are needed to determine the association between BMP9 and these signaling pathways.

The hepatic vagus nerve is important for relaying CNS signals to the liver to regulate HGP (Luo et al. 2016). In this study, we found that the effect of hypothalamic BMP9 on glucose metabolism can be abrogated by HVG, suggesting that hypothalamic BMP9 signals are also relayed to the liver through vagal efferent nerve fibers. Our findings 


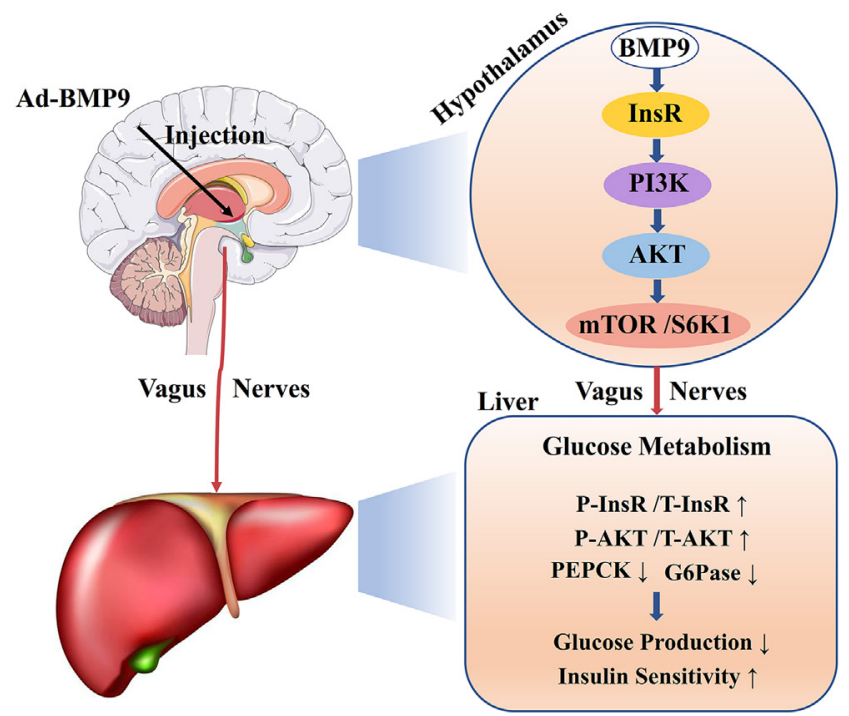

Figure 6

A model illustrating the working hypothesis of hypothalamic BMP9 signaling.

indicate a potential pathway for the transmission of BMP9 signals from the CNS to the liver and suggest that hypothalamic mTOR/S6K signaling and vagal innervation are essential for mediating the metabolic effects of hypothalamic BMP9. Thus, BMP9 may be considered as a neuro-regulated cytokine that acts through the canonical mTOR/S6K pathway in the hypothalamus, and this signal is finally relayed to the liver by vagal efferent for regulating HGP.

There were also some limitations in the current study, such as we did not use genetic animal models with BMP9 deficiency. Therefore, the interference of endogenous BMP9 cannot be excluded. Furthermore, we also cannot rule out that the effect of BMP9 on glucose metabolism may be secondary to weight loss.

\section{Conclusion}

The current study revealed that BMP9 is expressed in the hypothalamus and is downregulated under conditions of genetic- or HFD-induced IR. We showed that BMP9 overexpression in the hypothalamus of obese animals improves IR by promoting the ability of insulin to activate the InsR/PI3K/Akt/mTOR pathway. The InsR/PI3K/mTOR signaling cascade has been reported to induce $\mathrm{K}_{\text {ATP }}$ channel activation and membrane hyperpolarization to decrease the firing rate of hypothalamic neurons. Finally, the vagal efferent signals are triggered and relayed to the liver to regulate hepatic glucose fluxes and insulin signaling.
Thus, we illustrated a possible brain-liver axis, as shown in Fig. 6. This neuronal circuitry will help increase our understanding of the central regulation of BMP9 in energy homeostasis, as it pertains to obesity and IR.

Supplementary materials

This is linked to the online version of the paper at https://doi.org/10.1530/ JOE-19-0591.

\section{Declaration of interest}

The authors declare that there is no conflict of interest that could be perceived as prejudicing the impartiality of the research reported.

\section{Funding}

This work was supported by grants from the National Natural Science Foundation (No. 81873658).

\section{Data statement}

All data points were included in our reported analysis.

\section{Author contribution statement}

Y H, C Z, M L and J C researched and analyzed the data. H F G reviewed and edited the manuscript. $Y L$ contributed to the writing of the manuscript and helpful discussion. H F G reviewed and edited the manuscript. L L contributed to wrote, reviewed, and edited the manuscript. $Y \mathrm{G}$ and $X Z$ are the guarantor of this work and have full access to all the data in the study and takes responsibility for the integrity of the data and the accuracy of the data analysis.

\section{References}

Barahona MJ, Llanos P, Recabal A, Escobar-Acuna K, Elizondo-Vega R, Salgado M, Ordenes P, Uribe E, Sepulveda FJ, Araneda RC, et al. 2018 Glial hypothalamic inhibition of GLUT2 expression alters satiety, impacting eating behavior. Glia 66 592-605. (https://doi.org/10.1002/ glia.23267)

Blouet C, Ono H \& Schwartz GJ 2008 Mediobasal hypothalamic P70 S6 kinase 1 modulates the control of energy homeostasis. Cell Metabolism 8 459-467. (https://doi.org/10.1016/j.cmet.2008.10.004)

Boini KM, Hennige AM, Huang DY, Friedrich B, Palmada M, Boehmer C, Grahammer F, Artunc F, Ullrich S, Avram D, et al. 2006 Serum- and glucocorticoid-inducible kinase 1 mediates salt sensitivity of glucose tolerance. Diabetes 55 2059-2066. (https://doi.org/10.2337/db051038)

Caperuto LC, Anhe GF, Cambiaghi TD, Akamine EH, Do Carmo Buonfiglio D, Cipolla-Neto J, Curi R \& Bordin S 2008 Modulation of bone morphogenetic protein- 9 expression and processing by insulin, glucose, and glucocorticoids: possible candidate for hepatic insulinsensitizing substance. Endocrinology 149 6326-6335. (https://doi. org/10.1210/en.2008-0655) 
Chen D, Zhao M \& Mundy GR 2004 Bone morphogenetic proteins. Growth Factors 22 233-241. (https://doi.org/10.1080/0897719041233 1279890)

Contreras C, Gonzalez-Garcia I, Martinez-Sanchez N, Seoane-Collazo P, Jacas J, Morgan DA, Serra D, Gallego R, Gonzalez F, Casals N, et al. 2014 Central ceramide-induced hypothalamic lipotoxicity and ER stress regulate energy balance. Cell Reports 9 366-377. (https://doi. org/10.1016/j.celrep.2014.08.057)

Cota D, Proulx K, Smith KA, Kozma SC, Thomas G, Woods SC \& Seeley RJ 2006 Hypothalamic mTOR signaling regulates food intake. Science 312 927-930. (https://doi.org/10.1126/science.1124147)

Cota D, Matter EK, Woods SC \& Seeley RJ 2008 The role of hypothalamic mammalian target of rapamycin complex 1 signaling in dietinduced obesity. Journal of Neuroscience 28 7202-7208. (https://doi. org/10.1523/JNEUROSCI.1389-08.2008)

Dattatreyamurty B, Roux E, Horbinski C, Kaplan PL, Robak LA, Beck HN, Lein P, Higgins D \& Chandrasekaran V 2001 Cerebrospinal fluid contains biologically active bone morphogenetic protein-7. Experimental Neurology 172 273-281. (https://doi.org/10.1006/ exnr.2001.7728)

de Moura RF, Nascimento LF, Ignacio-Souza LM, Morari J, Razolli DS, Solon C, De Souza GF, Festuccia WT \& Velloso LA 2016 Hypothalamic stearoyl-CoA desaturase-2 (SCD2) controls whole-body energy expenditure. International Journal of Obesity $\mathbf{4 0} 471-478$. (https://doi. org/10.1038/ijo.2015.188)

Ebendal T, Bengtsson H \& Soderstrom S 1998 Bone morphogenetic proteins and their receptors: potential functions in the brain. Journal of Neuroscience Research 51 139-146. (https://doi.org/10.1002/ (SICI)1097-4547(19980115)51:2<139::AID-JNR2>3.0.CO;2-E)

Hu F, Xu Y \& Liu F 2016 Hypothalamic roles of mTOR complex I: integration of nutrient and hormone signals to regulate energy homeostasis. American Journal of Physiology: Endocrinology and Metabolism 310 E994-E1002. (https://doi.org/10.1152/ ajpendo.00121.2016)

Inquimbert P, Moll M, Kohno T \& Scholz J 2013 Stereotaxic injection of a viral vector for conditional gene manipulation in the mouse spinal cord. Journal of Visualized Experiments 73 e50313. (https://doi. org/10.3791/50313)

Kadowaki T, Yamauchi T, Kubota N, Hara K, Ueki K \& Tobe K 2006 Adiponectin and adiponectin receptors in insulin resistance, diabetes, and the metabolic syndrome. Journal of Clinical Investigation 116 1784-1792. (https://doi.org/10.1172/JCI29126)

Kim YB, Uotani S, Pierroz DD, Flier JS \& Kahn BB 2000 In vivo administration of leptin activates signal transduction directly in insulin-sensitive tissues: overlapping but distinct pathways from insulin. Endocrinology 141 2328-2339. (https://doi.org/10.1210/ endo.141.7.7536)

Kishigami S \& Mishina Y 2005 BMP signaling and early embryonic patterning. Cytokine and Growth Factor Reviews 16 265-278. (https:// doi.org/10.1016/j.cytogfr.2005.04.002)

Knight CM, Gutierrez-Juarez R, Lam TK, Arrieta-Cruz I, Huang L, Schwartz G, Barzilai N \& Rossetti L 2011 Mediobasal hypothalamic SIRT1 is essential for resveratrol's effects on insulin action in rats. Diabetes 60 2691-2700. (https://doi.org/10.2337/db10-0987)

Könner AC, Janoschek R, Plum L, Jordan SD, Rother E, Ma X, Xu C, Enriori P, Hampel B, Barsh GS, et al. 2007 Insulin action in AgRPexpressing neurons is required for suppression of hepatic glucose production. Cell Metabolism 5 438-449. (https://doi.org/10.1016/j. cmet.2007.05.004)

Kooijman S, Wang Y, Parlevliet ET, Boon MR, Edelschaap D, Snaterse G, Pijl H, Romijn JA \& Rensen PC 2015 Central GLP-1 receptor signalling accelerates plasma clearance of triacylglycerol and glucose by activating brown adipose tissue in mice. Diabetologia 58 2637-2646. (https://doi.org/10.1007/s00125-015-3727-0)

Kuo MM, Kim S, Tseng CY, Jeon YH, Choe S \& Lee DK 2014 BMP-9 as a potent brown adipogenic inducer with anti-obesity capacity. Biomaterials 35 3172-3179. (https://doi.org/10.1016/j biomaterials.2013.12.063)

Lam CK, Chari M, Rutter GA \& Lam TK 2011 Hypothalamic nutrient sensing activates a forebrain-hindbrain neuronal circuit to regulate glucose production in vivo. Diabetes 60 107-113. (https://doi. org/10.2337/db10-0994)

Li L, Yang G, Shi S, Yang M, Liu H \& Boden G 2009 The adipose triglyceride lipase, adiponectin and visfatin are downregulated by tumor necrosis factor-alpha (TNF-alpha) in vivo. Cytokine 45 12-19. (https://doi.org/10.1016/j.cyto.2008.10.006)

Li L, Miao Z, Liu R, Yang M, Liu H \& Yang G 2011 Liraglutide prevents hypoadiponectinemia-induced insulin resistance and alterations of gene expression involved in glucose and lipid metabolism. Molecular Medicine 17 1168-1178. (https://doi.org/10.2119/ molmed.2011.00051)

Lopez-Coviella I, Berse B, Krauss R, Thies RS \& Blusztajn JK 2000 Induction and maintenance of the neuronal cholinergic phenotype in the central nervous system by BMP-9. Science 289 313-316. (https:// doi.org/10.1126/science.289.5477.313)

Luo X, Li K, Zhang C, Yang G, Yang M, Jia Y, Zhang L, Ma ZA, Boden G \& Li L 2016 Central administration of vaspin inhibits glucose production and augments hepatic insulin signaling in high-fatdiet-fed rat. International Journal of Obesity 40 947-954. (https://doi. org/10.1038/ijo.2016.24)

Luo Y, Li L, Xu X, Wu T, Yang M, Zhang C, Mou H, Zhou T, Jia Y, Cai C, et al. 2017 Decreased circulating BMP-9 levels in patients with Type 2 diabetes is a signature of insulin resistance. Clinical Science $\mathbf{1 3 1}$ 239-246. (https://doi.org/10.1042/CS20160543)

Mahli A, Seitz T, Beckroge T, Freese K, Thasler WE, Benkert M, Dietrich P, Weiskirchen R, Bosserhoff A \& Hellerbrand C 2019 Bone morphogenetic protein-8B expression is induced in steatotic hepatocytes and promotes hepatic steatosis and inflammation in vitro. Cells 8 457. (https://doi.org/10.3390/cells8050457)

Martins L, Seoane-Collazo P, Contreras C, Gonzalez-Garcia I, MartinezSanchez N, Gonzalez F, Zalvide J, Gallego R, Dieguez C, Nogueiras R, et al. 2016 A functional link between AMPK and orexin mediates the effect of BMP8B on energy balance. Cell Reports 16 2231-2242. (https://doi.org/10.1016/j.celrep.2016.07.045)

Miller AF, Harvey SA, Thies RS \& Olson MS 2000 Bone morphogenetic protein-9. An autocrine/paracrine cytokine in the liver. Journal of Biological Chemistry 275 17937-17945. (https://doi.org/10.1074/ jbc.275.24.17937)

Mori H, Inoki K, Munzberg H, Opland D, Faouzi M, Villanueva EC, Ikenoue T, Kwiatkowski D, Macdougald OA, Myers Jr MG, et al. 2009 Critical role for hypothalamic mTOR activity in energy balance. Cell Metabolism 9 362-374. (https://doi.org/10.1016/j. cmet.2009.03.005)

Nectow AR, Moya MV, Ekstrand MI, Mousa A, Mcguire KL, Sferrazza CE, Field BC, Rabinowitz GS, Sawicka K, Liang Y, et al. 2017 Rapid molecular profiling of defined cell types using viral TRAP. Cell Reports 19 655-667. (https://doi.org/10.1016/j.celrep.2017.03.048)

Niswender KD, Morrison CD, Clegg DJ, Olson R, Baskin DG, Myers MG, Seeley RJ \& Schwartz MW 2003 Insulin activation of phosphatidylinositol 3-kinase in the hypothalamic arcuate nucleus: a key mediator of insulin-induced anorexia. Diabetes 52 227-231. (https://doi.org/10.2337/diabetes.52.2.227)

Ohyama K, Das R \& Placzek M 2008 Temporal progression of hypothalamic patterning by a dual action of BMP. Development 135 3325-3331. (https://doi.org/10.1242/dev.027078)

Ono H, Pocai A, Wang Y, Sakoda H, Asano T, Backer JM, Schwartz GJ \& Rossetti L 2008 Activation of hypothalamic S6 kinase mediates diet-induced hepatic insulin resistance in rats. Journal of Clinical Investigation 118 2959-2968. (https://doi.org/10.1172/JCI34277)

Pellegrinelli V, Peirce VJ, Howard L, Virtue S, Turei D, Senzacqua M, Frontini A, Dalley JW, Horton AR, Bidault G, et al. 2018 Adipocytesecreted BMP8b mediates adrenergic-induced remodeling of the https://joe.bioscientifica.com https://doi.org/10.1530/JOE-19-0591 (c) 2021 Society for Endocrinology Published by Bioscientifica Ltd. Printed in Great Britain 
neuro-vascular network in adipose tissue. Nature Communications 9 4974. (https://doi.org/10.1038/s41467-018-07453-x)

Purkayastha S, Zhang H, Zhang G, Ahmed Z, Wang Y \& Cai D 2011 Neural dysregulation of peripheral insulin action and blood pressure by brain endoplasmic reticulum stress. PNAS 108 2939-2944. (https:// doi.org/10.1073/pnas.1006875108)

Quaresma PG, Weissmann L, Zanotto TM, Santos AC, De Matos AH, Furigo IC, Simabuco FM, Donato J, Bittencourt JR, Lopes-Cendes JC, et al. 2017 Cdc2-like kinase 2 in the hypothalamus is necessary to maintain energy homeostasis. International Journal of Obesity $\mathbf{4 1}$ 268-278. (https://doi.org/10.1038/ijo.2016.174)

Sahu M, Anamthathmakula P \& Sahu A 2017 Hypothalamic phosphodiesterase 3B pathway mediates anorectic and body weightreducing effects of insulin in male mice. Neuroendocrinology $\mathbf{1 0 4}$ 145-156. (https://doi.org/10.1159/000445523)

Saltiel AR \& Kahn CR 2001 Insulin signalling and the regulation of glucose and lipid metabolism. Nature $\mathbf{4 1 4}$ 799-806. (https://doi. org/10.1038/414799a)

Saxton RA \& Sabatini DM 2017 MTOR signaling in growth, metabolism, and disease. Cell 168 960-976. (https://doi.org/10.1016/j. cell.2017.02.004)

Schenk S, Saberi M \& Olefsky JM 2008 Insulin sensitivity: modulation by nutrients and inflammation. Journal of Clinical Investigation 118 2992-3002. (https://doi.org/10.1172/JCI34260)

Schulz TJ \& Tseng YH 2009 Emerging role of bone morphogenetic proteins in adipogenesis and energy metabolism. Cytokine and Growth Factor Reviews 20 523-531. (https://doi.org/10.1016/j. cytogfr.2009.10.019)

Song JJ, Celeste AJ, Kong FM, Jirtle RL, Rosen V \& Thies RS 1995 Bone morphogenetic protein-9 binds to liver cells and stimulates proliferation. Endocrinology 136 4293-4297. (https://doi.org/10.1210/ endo.136.10.7664647)

Stevanovic D, Trajkovic V, Muller-Luhlhoff S, Brandt E, Abplanalp W, Bumke-Vogt C, Liehl B, Wiedmer P, Janjetovic K, Starcevic V, et al. 2013 Ghrelin-induced food intake and adiposity depend on central mTORC1/S6K1 signaling. Molecular and Cellular Endocrinology 381 280-290. (https://doi.org/10.1016/j. mce.2013.08.009)
Tobin JF \& Celeste AJ 2006 Bone morphogenetic proteins and growth differentiation factors as drug targets in cardiovascular and metabolic disease. Drug Discovery Today 11 405-411. (https://doi.org/10.1016/j. drudis.2006.03.016)

Townsend KL, Suzuki R, Huang TL, Jing E, Schulz TJ, Lee K, Taniguchi CM, Espinoza DO, Mcdougall LE, Zhang H, et al. 2012 Bone morphogenetic protein 7 (BMP7) reverses obesity and regulates appetite through a central mTOR pathway. FASEB Journal $\mathbf{2 6}$ 2187-2196. (https://doi.org/10.1096/fj.11-199067)

Tschöp MH, Speakman JR, Arch JR, Auwerx J, Brüning JC, Chan L, Eckel RH, Farese RV, Galgani JE, Hambly C, et al. 2011 A guide to analysis of mouse energy metabolism. Nature Methods 9 57-63. (https://doi.org/10.1038/nmeth.1806)

Whittle AJ, Carobbio S, Martins L, Slawik M, Hondares E, Vazquez MJ, Morgan D, Csikasz RI, Gallego R, Rodriguez-Cuenca S, et al. 2012 BMP8B increases brown adipose tissue thermogenesis through both central and peripheral actions. Cell 149 871-885. (https://doi org/10.1016/j.cell.2012.02.066)

Wu D, Yang M, Chen Y, Jia Y, Ma ZA, Boden G, Li L \& Yang G 2014 Hypothalamic nesfatin-1/NUCB2 knockdown augments hepatic gluconeogenesis that is correlated with inhibition of mTOR-STAT3 signaling pathway in rats. Diabetes 63 1234-1247. (https://doi. org/10.2337/db13-0899)

Yamamoto Y \& Oelgeschlager M 2004 Regulation of bone morphogenetic proteins in early embryonic development. Naturwissenschaften $\mathbf{9 1}$ 519-534. (https://doi.org/10.1007/s00114-004-0575-Z)

Yang M, Zhang Z, Wang C, Li K, Li S, Boden G, Li L \& Yang G 2012 Nesfatin-1 action in the brain increases insulin sensitivity through Akt/AMPK/TORC2 pathway in diet-induced insulin resistance. Diabetes 61 1959-1968. (https://doi.org/10.2337/db11-1755)

Yang M, Wang J, Wu S, Yuan L, Zhao X, Liu C, Xie J, Jia Y, Lai Y, Zhao AZ, et al. 2017 Duodenal GLP-1 signaling regulates hepatic glucose production through a PKC-delta-dependent neurocircuitry. Cell Death and Disease 8 e2609. (https://doi.org/10.1038/cddis.2017.28)

Zhang Q, Yu J, Liu B, Lv Z, Xia T, Xiao F, Chen S \& Guo F 2013 Central activating transcription factor 4 (ATF4) regulates hepatic insulin resistance in mice via S6K1 signaling and the vagus nerve. Diabetes 62 2230-2239. (https://doi.org/10.2337/db12-1050)

Received in final form 9 November 2020

Accepted 16 December 2020

Accepted Manuscript published online 19 December 2020 (c) 2021 Society for Endocrinology Published by Bioscientifica Ltd. Printed in Great Britain 